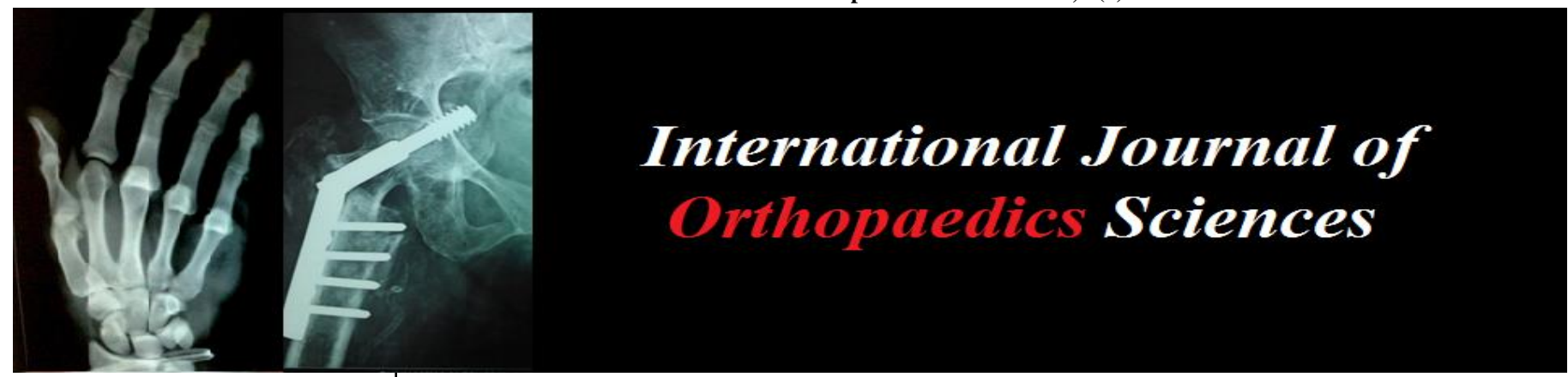

E-ISSN: 2395-1958

P-ISSN: 2706-6630

IJOS 2020; 6(3): 54-59

(C) 2020 IJOS

www.orthopaper.com

Received: 04-05-2020

Accepted: 06-06-2020

\section{Dr. Rajesh Thunuguntla}

Senior Resident, Department of

Orthopaedics, NRI Medical

College \& Hospital, Chinakakani,

Andhra Pradesh, India

Dr. Ramireddy Mettu

Associate Professor, Department of Orthopaedics, NRI Medical

College \& Hospital, Chinakakani,

Guntur, Andhra Pradesh, India

Dr. Kishore B Reddy

Senior consultant, Department of Orthopaedics, SUNSHINE

Hospitals, Secunderabad,

Telangana, India

Dr. AV Gurava Reddy

HOD, Department of

Orthopaedics, SUNSHINE

Hospitals, Secunderabad,

Telangana, India
Corresponding Author:

Dr. Ramireddy Mettu

Associate Professor, Department of Orthopaedics, NRI Medical

College \& Hospital, Chinakakani,

Guntur, Andhra Pradesh, India

\title{
A retrospective and prospective study of functional outcome of surgical management of acetabular fractures
}

\section{Dr. Rajesh Thunuguntla, Dr. Ramireddy Mettu, Dr. Kishore B Reddy and Dr. AV Gurava Reddy}

DOI: https://doi.org/10.22271/ortho.2020.v6.i3b.2177

Abstract

Background: Acetabular fractures are fractures that extend into the hip joint and pose a challenge for orthopaedic trauma surgeons

Objective: The aim of the present study was to evaluate the functional outcome of surgically treated acetabular fractures.

Methods: A prospective longitudinal study was undertaken in this hospital during the period from February 2012 to December 2014. A total number of 52 patients with the diagnosis of acetabular fracture were included in the study. The main cause of the acetabular injury was a road traffic accident. All the patients were treated surgically with plates and screws. Outcome was assessed radiologically and functionally, employing the Matta's radiological criteria. The mean follow-up period of the patients in the postoperative period was 30 months (24-36months).

Results: In the present study, Majority of the patients were Males 46 (88.46\%). Major injuries were caused by Road accidents. All Posterior wall, Posterior column, Associated Posterior Column and Posterior wall fractures were managed with open reduction and internal fixation through KocherLangenback approach with patient in lateral position. In the present study, we observed emergency closed reduction in 8 patients and open reduction done along with fixation in 6 patients. According to radiological assessment $75 \%$ were excellent and good. Whereas functional assessment made by Modified Merle d'Aubigne Scale, more than $80.76 \%$ patients were satisfied with the results of acetabular surgeries. In the present study, post-operative complications of acetabular fracture such as heterotopic ossification were found in $2.17 \%$, skin infections in 4.34 and vascular necrosis in $4.34 \%$ of patients.

Conclusion: These results show that internal fixation of acetabular fractures leads to a good outcome in the majority of patients. Early surgical intervention and experienced management is a prime factor in achieving good results.

Keywords: Acetabular fracture, kocher langenbeck, heterotropic ossification, radiological assessment

\section{Introduction}

Acetabular fractures are increasing worldwide at rapid pace due to increase in rail and road traffic accidents and high velocity injuries. Other type of injuries like fall from height, mine accidents also contribute to the rapid increase in incidence of these injuries. These fractures are often associated with other life-threatening injuries. Fractures of the acetabulum commonly result from high energy trauma. Frequently associated with other musculoskeletal and visceral injuries. Advanced Trauma Life Support (ATLS) evaluation sequence should be followed to rule out life or limb threatening conditions.

Acetabular fractures occurs when the head of the femur is driven into the pelvis, either by blow on the side of hip or by a blow on the front of knee with the hip in flexion and abduction (Dash board injury). The fracture pattern depends on the position of hip, direction of impact, magnitude of impact, and strength of the bone at the time of injury.

The treatment of acetabular fractures is a complex area of orthopaedics that is being continually refined. Most acetabular fractures that require operative treatment, open reduction and internal fixation with concentric reduction of femoral head beneath the anatomically reconstructed dome of acetabulum. 
These fractures are best treated at a specialized center by surgeons who routinely treat such injuries. If left untreated, displaced acetabular fractures can lead to the development of premature osteoarthritis of the hip.

Fractures of acetabulum and pelvis constitute only $2 \%$ of all fractures 1, 2, but they are associated with significant morbidity and mortality due to associated injuries. Several studies demonstrated that accurate reduction and rigid internal fixation can decrease

\section{Materials and Methods \\ Study Design}

We conducted a Retrospective and Prospective analysis of all acetabular fractures presented to the casualty at Sunshine Hospitals, operated during the period of February 2012 to December 2014. All acetabular fractures in both sexes with displacement greater than $2 \mathrm{~mm}$, were managed with operative treatment.

\section{Study Population}

The study includes the patients within the age group of 20-60 yrs. All cases were operated by a single trained surgeon in pelvic and acetabulum trauma. The follow-up period was 9 to 36 months, with an average of 18.5 months follow-up after surgery. The study group include a sample of 52 cases (6 female, 46 male) of displaced acetabular fractures, operated at level-I trauma hospital.

\section{Sample Size}

Included all the cases of acetabular fractures which were operated at Dept of Orthopaedics, SUNSHINE Hospital according to the inclusion and exclusion criteria. The sample to be considered as Purposeful Sampling which comes under Non-Probability Sampling.

\section{Inclusion criteria}

- Age: Age 20 - $60 \mathrm{yr}$, both sexes

- Displaced Acetabular anterior wall and posterior wall fractures (Displacement $>2 \mathrm{~mm}$ )

- Displaced Acetabular anterior column and posterior column (Displacement $>2 \mathrm{~mm}$ )

- Displaced Associated acetabular type fracture (displacement $>2 \mathrm{~mm}$ )

- Fractures operated within 2 wks after injury.

\section{Exclusion criteria}

- Age $>60$ yrs.

- Associated Osteoporosis

- Acetabular fractures presented after 2 wks of injury

- Associated Acetabular and femoral articular surface damage

- Patients with H/o hip Pain previous to injury

Associated comorbid conditions history of suffering from Myocardial Infarction (MI) less than 1year, psychiatric illness.

\section{Statistical analysis}

Data to be analyzed by using descriptive statistics.

\section{Results and Observations}

Gender Distribution: $(\mathbf{N}=52)$

In the present study, Number of male patients -46 and female patients were 6 ;

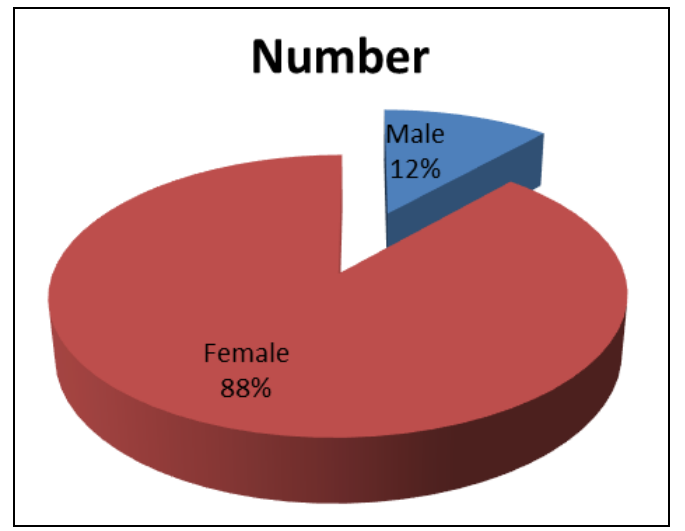

Fig 1: Gender distribution

Four cases are excluded from the study which tends to alter the interpretation of functional outcome, one bilateral acetabular fracture with open book pelvic injury, One patient underwent above knee amputation due to vascular injury, Two cases lost follow-up.

\section{Mode of injury}

The mechanism of injury, most common is road traffic accident, 39 cases reported in our study (18 cases--4wheeler RTA , 15 cases--2wheeler RTA ,6 cases --motor tricycle RTA, 5 Cases --fall from height, 6 Cases with pedestrian and other injuries.)

Acetabular fractures are usually associated with head injuries, blunt injury chest and blunt injury abdomen which are evaluated for the severity followed by evaluation of acetabular fractures with $\mathrm{X}$ - ray antero-posterior view. Judet views are not done routinely as pain precludes us taking the oblique views. Once the patient stabilised haemodynamically, then $\mathrm{CT}$ scan with $3 \mathrm{D}$ reconstruction was done.

Acetabular fractures with posterior hip dislocation are managed with emergency closed reduction of hip under appropriate anaesthesia care followed by skeletal traction maintaining the reduction. Failed closed reduction cases are posted for emergency open reduction and immediate fracture fixation.

Table 1: mode of injury in our study

\begin{tabular}{|c|c|}
\hline Mode of injury & Number of cases \\
\hline Road traffic accidents & 39 \\
\hline Fall from height & 6 \\
\hline Miscellaneous & 7 \\
\hline
\end{tabular}

No iatrogenic sciatic nerve injury occurred during our study

Table 2: Type of fracture: $(\mathrm{N}=52)$

\begin{tabular}{|c|c|}
\hline Type of fracture & Number of cases \\
\hline Posterior wall & 16 \\
\hline Posterior column & 5 \\
\hline Anterior wall & 0 \\
\hline Anterior column & 2 \\
\hline Transverse & 7 \\
\hline T Shaped & 5 \\
\hline Transverse + Posterior wall & 5 \\
\hline Posterior column + Posterior wall & 9 \\
\hline Bnterior column + Posterior hemi transverse & 0 \\
\hline Total column & 5 \\
\hline
\end{tabular}




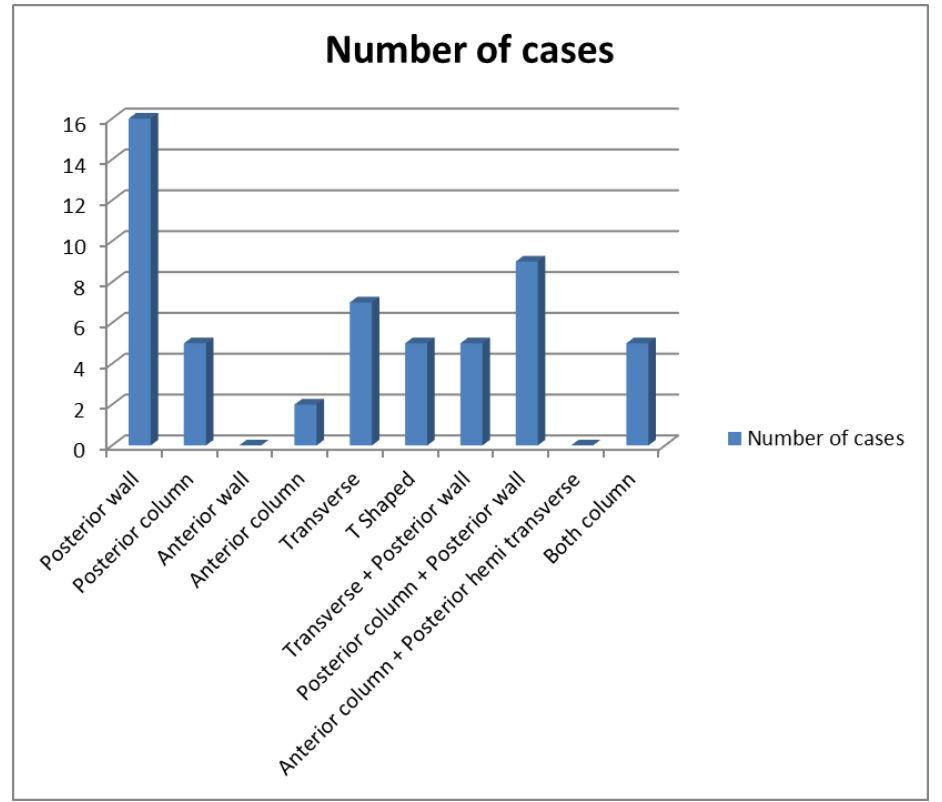

Fig 2: Fracture Distribution in our study

\section{Associated hip dislocation \& Reduction of dislocation}

In the present study, we observed emergency closed reduction in 8 patients and open reduction done along with fixation in 6 patients.

\section{Time delay for surgery}

$\begin{array}{lll}\text { Minimum delay } & : & 1 \text { day } \\ \text { Maximum delay } & : & 13 \text { days } \\ \text { Mean } & : & 3.5 \text { days }\end{array}$

\section{Approach}

All acetabular fractures managed surgically either with Ilioinguinal approach or Kocher-Lagenback approach or combined surgical approach. The choice of the appropriate surgical approach is decided at first stage of the surgical decision making. This is done in relation to three factors: the anatomic type of fracture as determined from radiographic study, the extent of access offered to the pelvis by the different surgical approaches, and the timing of surgery as it relates to the extent of fracture healing that may have occurred. In general, the older a fracture the greater the exposure required for acceptable reduction.

Table 3: Approach used in our study

\begin{tabular}{|c|c|}
\hline Approach & No. of patients \\
\hline Kocher-Langenbeck & 26 \\
\hline Ilioinguinal & 2 \\
\hline Iliinguinal +Kocher-Langenbeck & 24 \\
\hline
\end{tabular}

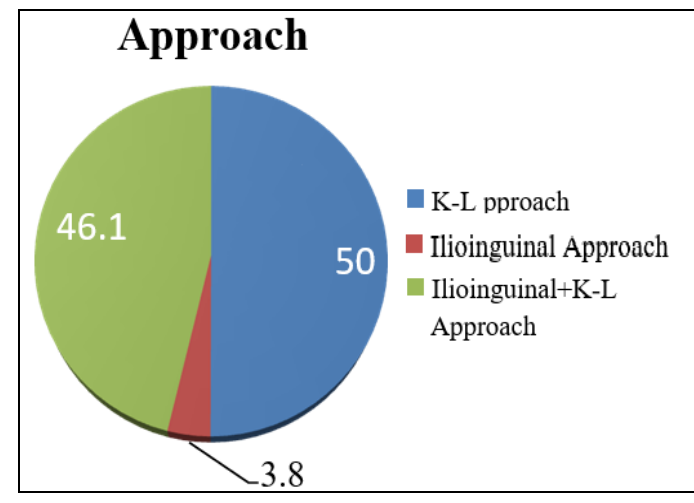

Fig 3: Approach used in our study
All Posterior wall, Posterior column, Associated Posterior Column and Posterior wall fractures were managed with open reduction and internal fixation through Kocher- Langenback approac with patient in lateral postion.

All Transverse fractures were managed with open reduction of Posterior column through K-L Approach with patient in lateral position, followed by change of position to supine position and fixation of anterior column through Ilioinguinal approach.

The choice of fixation in $\mathrm{T}$ fractures were managed with combined Ilioinguinal and Kocher - Langenbeck, the lesser comminuted side was chosen to be fixed first to get the anatomical reduction followed by severely comminuted part.

All Both Column fractures were managed by anterior column fixation through Ilioinguinal in supine position followed by posterior column fixation through Kocher- Langenbeck approach, Anterior column with Posterior hemitransvertse fractures were managed by anterior column fixation through Ilioinguinal approach in supine position followed by posterior column fixation through in lateral position.

Elementary anterior column fractures by anterior column fixation through Ilio- inguinal approach in supine position.

The choice of implant being a combination of various implants recon plate, spring plate, semitubular plate depending upon fracture geometry. The quality of reduction is assessed by post-operative antero-posterior and oblique views and graded as described by Matta radiological assessment.

Passive Range of Movement started on the second postoperative day. Walking without weight bearing on operated side is allowed at the $2^{\text {nd }}$ to $10^{\text {th }}$ day postoperatively (walker support). Partial weight bearing walking with walker support started 6 wks postoperatively. Full weight bearing walking started 12 weeks following surgery (If not associated with other limb injury, which may alter the protocol of weight bearing).

All cases are assessed by questionnaire and clinical examination which are included in Merle d'Aubigne Score. The initial assessment being done at $6 \mathrm{wk}$ followed by regular follow-ups at 3,6,9,12,18,24,30,36 months. At every follow up radiological assessment, using antero-posterior views and Judet views with Matta's radiological criteria. 


\section{Radiological Outcome}

Matta's Criteria-Reduction of Fracture

- Anatomic - 0-1 mm

- Good - 2-3 mm

- Poor - More than $3 \mathrm{~mm}$

\section{Matta Radiological Scoring Systems}

- Excellent - A normal appearing hip joint

- Good - Mild changes with minimal sclerosis and joint narrowing less than $1 \mathrm{~mm}$

- Fair - Intermediate changes with moderate sclerosis and joint narrowing less than $50 \%$

- Poor - Advanced changes

Table 4: Radiological assessment of fracture reduction (Matta's Criteria-Reduction of Fracture)

\begin{tabular}{|c|c|}
\hline Reduction & No. of patients \\
\hline Anatomic $(0-1 \mathrm{~mm})$ & 39 \\
\hline Good $(2-3 \mathrm{~mm})$ & 10 \\
\hline Poor $(>3 \mathrm{~mm})$ & 2 \\
\hline
\end{tabular}

Table 5: Radiological assessment of joint degeneration (Matta Radiological Scoring Systems)

\begin{tabular}{|c|c|}
\hline Radiographic assessment & No. of cases \\
\hline Excellent & 30 \\
\hline Good & 15 \\
\hline Fair & 6 \\
\hline Poor & 1 \\
\hline
\end{tabular}

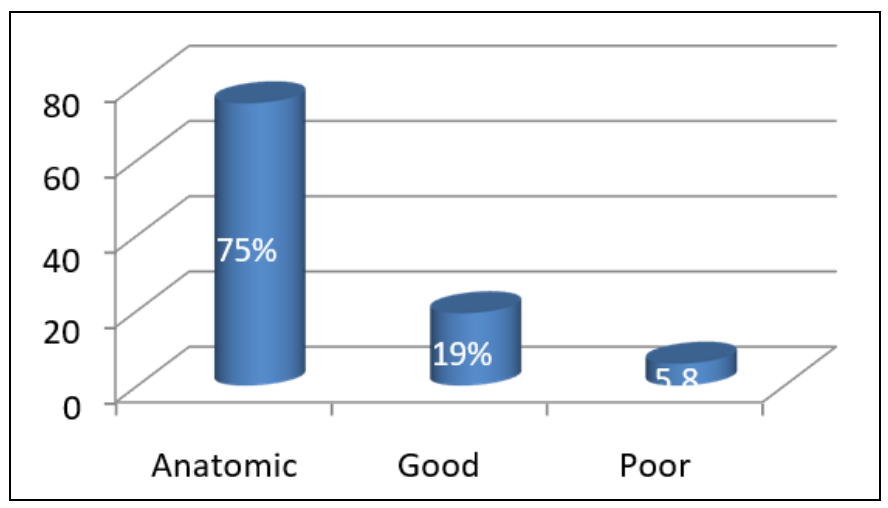

Fig 4: Radiological Assessment of fracture reduction
Functional Assessment-Modified Merle d'Aubigne Scale

- Pain (0-6)

- Walking (0-6)

- $\quad$ Range of Motion (0-6)

\begin{tabular}{|c|c|}
\hline \multicolumn{2}{|l|}{ Outcome } \\
\hline - Excellent & 10 \\
\hline - Good & $15-17$ \\
\hline $\begin{array}{ll}\text { - } & \text { Fair } \\
\text { - } & \text { Poor }\end{array}$ & $\begin{array}{l}13-14 \\
<13\end{array}$ \\
\hline
\end{tabular}

Functional Outcomes in our study $(\mathrm{N}=52)$

Table 6: Assessment of functional score

\begin{tabular}{|c|c|}
\hline Excellent & 16 \\
\hline Good & 26 \\
\hline Fair and Poor & $6+4$ \\
\hline
\end{tabular}

Mean functional score: 16.1

Table 7: Comparison with other published studies

\begin{tabular}{|c|c|c|c|}
\hline Published Studies & Cases & $\begin{array}{c}\text { Mean follow } \\
\text { up (Yrs) }\end{array}$ & $\begin{array}{c}\text { Excellent/ } \\
\text { Good (\%) }\end{array}$ \\
\hline Bircher et al. ${ }^{[3]}$ & 161 & 11.3 & 73 \\
\hline Madhu et al. ${ }^{[4]}$ & 237 & 2.9 & 76 \\
\hline Deo et al. ${ }^{[5]}$ & 74 & 2.6 & 74 \\
\hline Naseem Munshi et al. ${ }^{[6]}$ & 75 & 2 & 78.6 \\
\hline U.K Meena et al. ${ }^{77]}$ & 108 & 3.95 & 67.1 \\
\hline Our study & 52 & 1.4 & 80.8 \\
\hline
\end{tabular}

\section{Complications}

Two cases of infection occurred, one case of deep infection, resolved after debridement and implant removal, second case of infection, resolved with debridement and Intravenous antibiotic, but later presented with resorption of femoral head, advised for staged Total hip arthroplasty.

Table 8: Complication rate in our study

\begin{tabular}{|c|c|}
\hline Post operative complications & No. of cases \\
\hline Infection & 2 \\
\hline Avascular necrosis & 3 \\
\hline Heterotopic ossification & 2 \\
\hline DVT & 0 \\
\hline Iatrogenic sciatic nerve injury & 0 \\
\hline
\end{tabular}

Table 9: Complication rate compared with other published studies

\begin{tabular}{|c|c|c|c|c|c|c|c|}
\hline Study Name & $\begin{array}{c}\text { Infection } \\
(\boldsymbol{\%})\end{array}$ & $\begin{array}{c}\text { Heterotopic } \\
\text { ossificans }(\boldsymbol{\%})\end{array}$ & $\begin{array}{c}\text { Postoperative sciatic } \\
\text { Nerve injury (\%) }\end{array}$ & $\begin{array}{c}\text { AVN } \\
(\mathbf{\%})\end{array}$ & $\begin{array}{c}\text { DVT } \\
(\mathbf{\%})\end{array}$ & $\begin{array}{c}\text { Chondrolysis } \\
(\boldsymbol{\%})\end{array}$ & $\begin{array}{c}\text { Hardware } \\
\text { Failure (\%) }\end{array}$ \\
\hline U.K. Meena et al. ${ }^{[7]}$ & 5.9 & 8.5 & 2.5 & 11.9 & 2.5 & 2.5 & 1.7 \\
\hline P.V Giannoudis et al. ${ }^{[8]}$ & 4.4 & 5.7 & 8.0 & 5.6 & 4.3 & --- & -- \\
\hline Our Study & 3.8 & 3.8 & 0 & 5.7 & 0 & 0 & 0 \\
\hline
\end{tabular}

\section{Discussion}

Acetabular fractures are complex, high energy injuries and have the potential for a poor outcome regardless of the treatment method. The contributing factors may include an imperfect reduction, osteochondral defects in either the acetabulum or the femur at the time of injury, osteoarthritis, AVN of the femoral head, heterotropic ossification, sciatic nerve injury and infection ${ }^{[3]}$.

The majority of acetabular fractures are reduced and stabilised through one of two approaches, Kocher-Langenbeck or ilioinguinal approach. The main factors influencing choice of approach are the fracture type and the soft tissues. In general, any fracture that is classified as an anterior column fracture should be approached from the front, and any fracture classified as a posterior column fracture should be approached from the posterior side.

Sequential approaches gives the best of both views, but the surgeon must be careful to avoid fixation through the first approach that will compromise fracture reduction through the second.

Although a single large approach intuitively appears more attractive, the extensile approaches are associated with an increased operating time, blood loss, infection rates and complications such as heterotopic ossification. As the understanding of acetabular fractures and the steps required to reduce and stabilise them have improved over time, the larger 
exposures tend to be used less frequently. The objectives of an approach are not only exposure, but avoiding devascularisation of the bone, and where possible minimizing dissection is beneficial.

The aim of acetabular fracture surgery is to restore the joint surface anatomically and obtain stable fixation, thus enabling early mobility of a congruent joint. This allows for the best outcomes, both for the joint and the patient as a whole. Surgical procedures can be broken down into exposure, fracture identification, reduction, fixation and closure.

Direct Reduction - in the majority of posterior approaches the joint surface is seen through the posterior wall fracture, and the reduction manoeuvres are direct. After inspection of the joint, the fracture lines can be reduced with a combination of surgical dissection, limb traction and carefully applied pressure to the fragments.

Indirect Reduction usually done in ilio-inguinal approach where the articular surface is not seen, and no direct assessment can be made of the femoral head. Reduction manoeuvres involve limb traction and direct pressure on the fragments. An assumption regarding the joint surface reduction is made based on the reduction visible on the outer aspect of the acetabular bones. While the anterior column reduction is well seen through this approach, the reduction and orientation of the posterior column is less well appreciated. High posterior column fractures are within the field of vision but lower fractures less visible.

Factors such as mechanism of the injury, damage to the femoral head, sciatic nerve injury, dislocation, fracture pattern, associated injuries, the patient's age and comorbidities are not under surgeon's control. But, the timing of surgery, selection of surgical approach and quality of reduction and fixation are surgeon dependent factors which can affect the eventual outcome ${ }^{[9]}$.

The total of 52 displaced acetabular wall fractures of both sex, were included in our study. The most common mechanism of fracture is high velocity RTA contributing $75 \%$ of case study, followed by fall from height and pedestrian accidents contributing $15 \%$.

The mean follow-up period was 1.4 years ( 9 months -- 36 months). The mean age in our study is 41.8 years (20 to 60 years). In older age group, ambulatory status, activity level, bone quality, and medical comorbidities all must be considered, which may alter the assessment of functional score. All acetabular fractures with age greater than 60 yrs are excluded from our study.

There were 46 males $(88.5 \%)$ and females $(11.5 \%)$. This is in par most other studies, Naseem Munshi et al. ${ }^{[6]}$ with gender distribution of $69(92 \%)$ male patients and $9(12 \%)$ female patients. P. V. Giannoudis et al. ${ }^{[8]}$ Meta-analysis with gender distribution of male $70 \%$ and female $30 \%$.

The most common mode of injury in our study is road traffic accident. Naseem Munshi et al. ${ }^{[6]}$, RTA is most common mode of injury, contributing $88 \%$ of all acetabular fractures in their study.

P. V. Giannoudis et al. ${ }^{[8]}$, Metanalysis on acetabular wall fractures, states that road traffic accident was the causative mechanism in $80.5 \%$ of patients of all acetabular wall fractures.

The Letournel and Judet ${ }^{[9]}$ classification is used in our study, it was the most commonly used classification which has high intra-observer and inter-observer reliability, Beaule, Dorey and Matta ${ }^{[10]}$.

The fracture distribution in our study, Elementary fracture pattern in 24 cases $(46.1 \%)$ and associated fracture pattern in
28 cases (53.9\%). Posterior wall fracture was the most common, followed by Bicolumnar fracture and Transverse fracture with posterior wall fracture. P. V. Giannoudis et al. ${ }^{[8]}$ reported the more common types of acetabular fractures in their meta-analysis were of the posterior wall, bicolumnar and transverse with posterior wall fractures.

14 cases of posterior dislocation, were reported in our study, in 8 cases immediate closed reduction was done, in 6 cases where closed reduction is not acquired and closed reduction was unstable, open reduction and fracture stabilization was done. The hip dislocation rate in our study was $27 \%$. Briffa $e t$ al., ${ }^{[3]}$ reported hip dislocation rate of $33 \%$ in their study group.

We encountered 4 cases of foot drop at the time of presentation, 3 of them recovered from foot drop at the final follow up. One case was advised for tendon transfer at 18 months of follow-up.

Surgical delay is found to affect the quality of reduction and amount of dissection required for exposure of fracture site, Mears et al. ${ }^{[11]}$ found that if surgery was delayed for more than 11 days after injury, there were significantly fewer anatomical reductions. In our study, cases operated 2 weeks after injury were excluded. We tried to decrease the surgical delay in all the cases, with mean surgical delay of 3.5 days. As most of the cases are poly-trauma, the surgical delay is unavoidable. During this period, along with secondary and tertiary evaluation, patient general condition was optimised for the surgery.

The Kocher-Langenbeck approach is used most frequently in the operative treatment of acetabular fractures. ${ }^{[12,13]}$. In our study, Kocher-Langenbeck used in $26(50 \%)$ cases, Combined approach in $24(46.1 \%)$ cases and Iliinguinal approach in 2 $(3.8 \%)$ cases. Kocher-Langenbeck approach used in all posterior fractures, combined approach used in all transverse fracture, transverse with posterior wall fractures and Bicolumnar fractures, Ilioinguinal approach used in all anterior column fractures.

We achieved anatomic reduction with a gap $0-1 \mathrm{~mm}$ in 39 cases $(75 \%)$, good reduction with of $2-3 \mathrm{~mm}$ in 10 cases (19\%), and poor reduction with gap greater than $3 \mathrm{~mm}$ in 3 cases $(5.8 \%)$. The results according to Postel Modified Merle D_Aubigne scoring system was Excellent in 16 cases $(30 \%)$ good in $26(50 \%)$ cases contributing to $80 \%$. And Matta radiological scoring system results were excellent $\&$ good in 45 cases $(86 \%)$, fair and poor in $7(14 \%)$ cases.

P.V. Giannoudis et al. ${ }^{[8]}$, analysed the quality of reduction in 24 studies, documented the quality of reduction is satisfactory with gap less than $2 \mathrm{~mm}$ in $85.6 \%$ of fractures. Unsatisfactory reduction when gap greater than $2 \mathrm{~mm}$ in $14.4 \%$ of acetabular fractures.

Our results are comparable with other published outcomes. N. Briffa et al. [3] reported results according to the Postel Modified Merle $\mathrm{D}_{=}$Aubigne scoring system was excellent in 75 patients(47\%), good in $41(25 \%)$, fair in $12(7 \%)$ and poor in $33(20 \%)$

U.K Meena et al. ${ }^{[7]}$, retrospective analytical study in Indian population, reported clinical outcome was excellent in 27 $(22.9 \%)$, good in $52(44.2 \%)$, fair in $20(16.9 \%)$, and poor in $19(16.1 \%, 10$ patients who underwent THR for secondary arthritis were considered as poor outcome) patients.

The long-term results are influenced by numerous factors. The type of fracture and the quality of the reduction are the main influences on functional outcome ${ }^{[8]}$.

Other factors which influence functional outcome include increased age, delay in operative treatment, and the presence 
of damage to the femoral head 13

Osteoarthritis is the most common complication of acetabular fractures. Secondary OA reported was $14 \%$ in our study. The incidence of OA was related to the quality of reduction ${ }^{\text {[14-16]. }}$ If the reduction was satisfactory $(\leq 2 \mathrm{~mm})$, the incidence was $13.2 \%$.

If the reduction was not satisfactory (>2 mm), the incidence increases as high as $43.5 \%$. No case of iatrogenic sciatic nerve injury reported in our study.

DVT prophylaxis given with Enoxaparin $40 \mathrm{mg}$ once a day given, post-operatively till the patient is actively mobilized from the bed. No case of DVT reported in our study, early mobilization of patient and aggressive physiotherapy of the patient should be done to prevent DVT.

We had two cases of wound infection post operatively $(3.8 \%)$, which were managed with debridement, one case had persistent infection which was managed with implant removal, and two cases of heterotopic ossification (3.8\%) and 3 cases of AVN (5.7\%) were reported. The incidence of iatrogenic sciatic nerve injury was zero in our study. The incidence of various complications in our study and various other studies were made in the table.

\section{Conclusion}

Though many fracture variables like fracture comminution and marginal impaction were found to affect the functional outcome, optimisation of surgeon dependent factors like, time delay for surgery, choice of approach, amount of dissection and quality of reduction achieved on operating table, will improve the final functional outcome achieved. The gold standard treatment for acetabular fracture remains the anatomic reduction, stable internal fixation and aggressive physiotherapy with early mobilization of patient, postoperatively. Though short term results are good and encouraging we need longer follow-up to understand the long term results.

\section{Acknowledgement}

The author thankful to Department of Orthopedics, Sunshine Hospital for providing all the facilities to carry out this work.

\section{References}

1. Hesp WL, Goris RJ. Conservative treatment of fractures of the acetabulum. Results after longtime follow-up. Acta Chir Belg. 1988; 88(1):27-32.

2. Ragnarsson B, Jacobsson B. Epidemiology of pelvic fractures in a Swedish county. Acta Orthop Scand. 1992; 63(3):297-300.

3. Briffa N, Pearce R, Hill AM, Bircher M. Outcomes of acetabular fracture fixation with ten years' follow-up. J Bone Joint Surg Br. 2011; 93(2):229-36.

4. Madhu R, Kotnis R, Al-Mousawi A et al. Outcome of surgery for reconstruction of fractures of the acetabulum: the time dependent effect of delay. J Bone Joint Surg [Br] 2006; 88-B:1197-1203.

5. Deo SD, Tavares SP, Pandey RK et al. Operative management of acetabular fractures in Oxford. Injury 2001; 32:581-586.

6. Munshi $\mathrm{N}$ et al., Functional outcome of the surgical management of acute acetabular fractures, Journal of Acute Disease 2015, 1-4

7. Meena UK, Tripathy SK, Sen RK, Aggarwal S, Behera P. Department of Orthopaedics, Postgraduate Institute of Medical Education and Research, Sector-12, Chandigarh 160012. Orthopaedics \& Traumatology: Surgery \&
Research. 2013; 99:929-935.

8. Giannoudis PV et al Operative treatment of displaced fractures of the acetabulum 2005 British EditorialSociety of Bone and Joint Surgery doi:10.1302/0301-620X.87B1. 15605 J Bone Joint Surg [Br]. 2005; 87-B:2-9.

9. Letournel E, Judet R. Fractures of the acetabulum, 1st ed. Berlin: Springer-Verlag, 1981

10. Beaulé PE, Dorey FJ, Matta JM. Letournel classification for acetabular fractures. Assessment of interobserver and intraobserver reliability. 2003 85-A(9):1704-9.

11. Mears DC, Velyvis JH, Chang CP. Displaced acetabular fractures managed operatively: indicators of outcome. Clin Orthop. 2003; 407:173-86.

12. Kebaish AS, Roy A, Rennie W. Displaced acetabular fractures: long-term followup. J Trauma. 1991; 31:153942.

13. Liebergall M, Mosheiff $\mathrm{R}$, Low $\mathrm{J}$ et al. Acetabular fractures: clinical outcome of surgical treatment. Clin Orthop. 1999; 366:205-16.

14. Orthopaedic Trauma Association. A committee for coding and classification. J Orthop Trauma. 1996; 10(Suppl I):71-5.

15. Pantazopoulos T, Nicolopoulos CS, Babis GC, Theodoropoulos T. Surgical treatment of acetabular posterior wall fractures. Injury. 1993; 24:319-23.

16. Stöckle U, Hoffmann R, Sudkamp NP, Reindl R, Haas NP. Treatment of complex acetabular fractures through a modified extended iliofemoral approach. J Orthop Trauma. 2002; 16:220-30. 